\title{
Nursing Taxonomy and Studies of Efficacy, Efficiency and Effectiveness: A Challenge
}

\author{
Emilia Campos de Carvalho
}

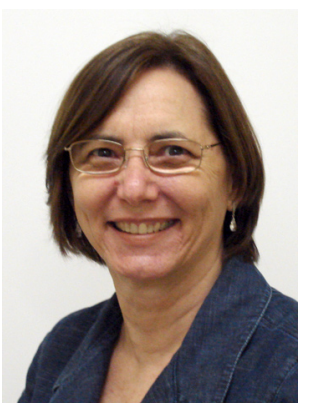

Since the 70's, literature has awoken nurses to the contributions that classifications available in Nursing, of phenomena, interventions or results, may offer in several aspects, even more when they brings information about the patients' or clients' conditions and facilitate clinical diagnostic and therapeutic thinking, enabling comparisons of data from different regions, projecting practice and management trends, and also giving information that helps to make the best possible decisions.

Concerns with knowledge production in this area and its application in Brazilian Nursing attest expectations regarding its use and potential.

Although still incipient, in Brazilian scientific production about studies using the Nursing Interventions Classification ${ }^{(1)}$ and, even more, the Classification of Nursing Results(2), contributions can already be identified in studies about the International Classification of Nursing Practice, especially those related to the CIPESC project, a taskforce of the Brazilian Nursing Association and, as an even greater contribution, studies referring to nursing diagnoses, mainly involving the taxonomy of the North American Nursing Diagnosis Association International.

Such studies mostly reference the upcoming, characteristics, architectural structure of the classifications, advantages and potentials of their use or, still, the creation or validations of these classifications' elements; other classifications exist, however, and can improve the discussion on this theme.

Studies that determine the benefit of certain technologies, as an intervention, programmed in ideal or experimental (efficacy studies) conditions, or clinical studies that evaluate the benefits of this intervention in usual conditions (effectiveness studies), or cost-effectiveness or cost-utility studies, for example, the use of diagnosis or result classifications (efficiency studies), as classified by some authors ${ }^{(5)}$, are still rare in our midst.

We hope the movement to use these tools in teaching, research and care becomes even stronger, also in Brazil, with efficacy, efficiency and effectiveness studies related to situations or problems of our reality, which can result in solid evidence of their benefit for the Nursing area and for the strengthening of Classifications. 


\section{References}

1. Napoleão AA, Chianca TCM, Dalri MCB, Carvalho EC. Análise da produção científica sobre a Classificação das Intervenções de Enfermagem (NIC) de 1980 a 2004. Rev. Latino-Am. Enfernagen. 2006; 14(4):608-15.

2. Seganfredo DH, Almeida MA. Produção de conhecimento sobre resultados de enfermagem. Rev. Bras Enf. 2010; 63(1):122-6.

3. Nita ME, Secoli SR, Nobre M, Ono-Nita SK. Métodos de pesquisa em avaliação de tecnologia em saúde. Arq Gastroenterol 2009; (4):252-55.

Emilia Campos de Carvalho is member of the Editorial Board of the Latin American Journal of Nursing, and Full Professor of the University of São Paulo at Ribeirão Preto College of Nursing, WHO Collaborating Centre for Nursing Research Development, Brazil, e-mail: ecdcava@usp.br. 